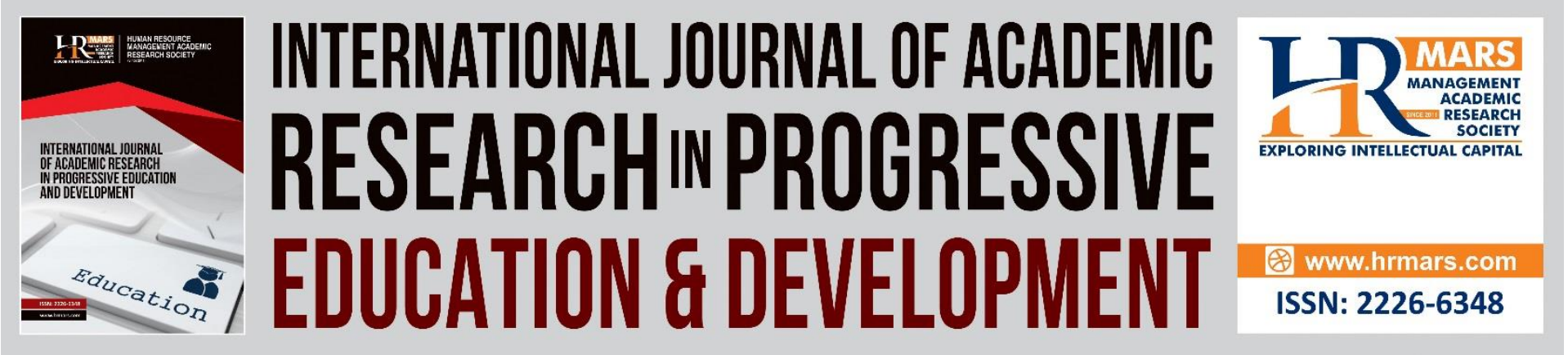

\title{
A Prospective Study of Acute Stroke Type, Risk Factors, Age and Sex Distribution in Eastern Region of Afghanistan
}

Samiullah Sajjad, Ajmal Ghayour, Abdullah Jan Shenwari

To Link this Article: http://dx.doi.org/10.6007/IJARPED/v11-i1/12228

DOI:10.6007/IJARPED/v11-i1/12228

Received: 04 December 2021, Revised: 07 January 2022, Accepted: 29 January 2022

Published Online: 12 February 2022

In-Text Citation: (Sajjad et al., 2022)

To Cite this Article: Sajjad, S., Ghayour, A., \& Shenwari, A. J. (2022). A Prospective Study of Acute Stroke Type, Risk Factors, Age and Sex Distribution in Eastern Region of Afghanistan. International Journal of Acdemic Research in Progressive Education and Development, 11(1), 631-637.

Copyright: (C) 2022 The Author(s)

Published by Human Resource Management Academic Research Society (www.hrmars.com)

This article is published under the Creative Commons Attribution (CC BY 4.0) license. Anyone may reproduce, distribute, translate and create derivative works of this article (for both commercial and non-commercial purposes), subject to full attribution to the original publication and authors. The full terms of this license may be seen

at: http://creativecommons.org/licences/by/4.0/legalcode

Vol. 11(1) 2022, Pg. 631 - 637

Full Terms \& Conditions of access and use can be found at http://hrmars.com/index.php/pages/detail/publication-ethics 


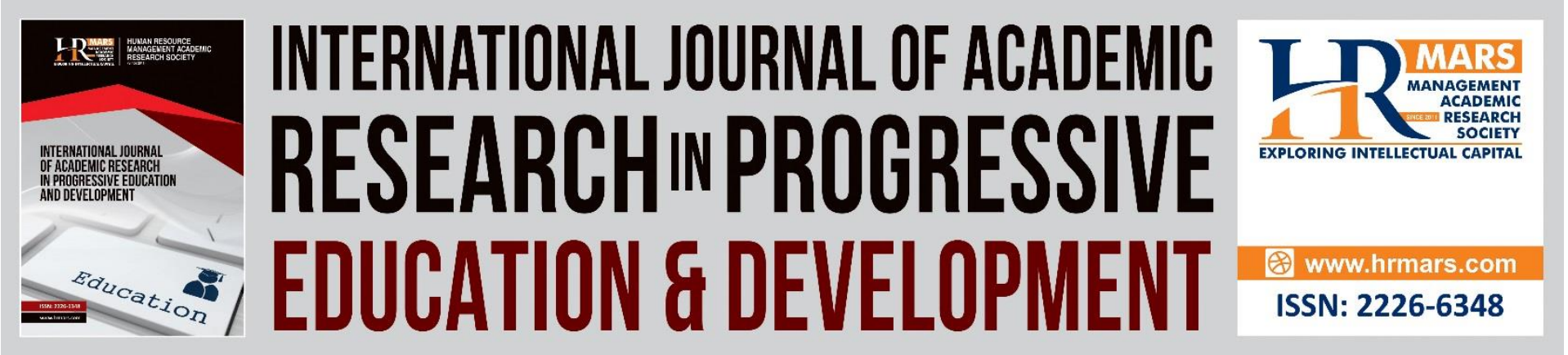

\title{
A Prospective Study of Acute Stroke Type, Risk Factors, Age and Sex Distribution in Eastern Region of Afghanistan
}

\author{
Assistant. Prof Dr Samiullah Sajjad ${ }^{1}$, Assistant. Prof Dr. Ajmal \\ Ghayour $^{2}$, Assistant. Prof Dr. Abdullah Jan Shenwari ${ }^{3}$ \\ ${ }^{1} \mathrm{MD}$. Department of Radiology, Nangarhar Medical Faculty, Jalalabad Afghanistan \\ ${ }^{2} \mathrm{MD}$. Department of Neuropsychiatry, Nangarhar Medical Faculty, Jalalabad Afghanistan. \\ ${ }^{3}$ MD.Department of Anatomy, Nangarhar Medical Faculty, Jalalabad Afghanistan
}

\begin{abstract}
Objective: This hospital-based prospective study was conducted to determine stroke type, risk factors, Age and Sex distribution in patients admitted with acute stroke in Nangarhar University Teaching Hospital located in East region of Afghanistan.

Methods: A retrospective study design was carried out to determine the types, risk factors, age and sex distribution of stroke during 2018/Nov-2020/Nov. The study sample included 401 stroke patients of the Nangarhar University Teaching Hospital. Consecutive stroke patients presenting within 48 hours of onset were included in the study. Data were obtained from history taking, physical examination, and investigations. Brain CT scan was performed for all patients so the diagnosis of stroke types was determined by Brain CT scan which was then statistically analyzed through frequencies and percentages.

Results: 401 patients, 215 (53.6\%) males and 186 (46.4\%) females, were studied. The peak age group was 61 to 70 years. Stroke caused by infarction was found in 309(77.1\%) while stroke caused by hemorrhage was found in 92(22.9\%). Hypertension was the most common associated risk factor 159(39.6\%), Ischemic Heart Disease was found in 63(15.7\%), Diabetes Mellitus in 58(14.4\%), previous transient ischemic attack 35(8.7\%), blood disorder16(3.9\%) ,obesity $14(3.4 \%)$ multiple risk factors56 (13.9\%). The overall mortality was higher than in western countries. Risk factors for stroke in eastern region of Afghanistan are the same as elsewhere; however, the peak age group is 2 decades earlier than in developed countries. In developing countries, promoting hypertension and acute stroke health care programs are essential to cutting morbidity and mortality rates.

Conclusion: stroke in eastern region of Afghanistan has similar risk factors as elsewhere, and its mortality is higher than in western and wealthier developed countries
\end{abstract}

Keywords: Afghanistan, Hypertension, Risk Factors, Stroke.

\section{Introduction}

A stroke is a medical condition in which poor blood flow to the brain causes cell death (Wolf, 1998).There are two main types of stroke, ischemic due to lack of blood flow, 
and hemorrhagic due to bleeding. Both cause parts of the brain to stop functioning properly (Bogousslavsky, 1997; Osuntoua, 1979).

Signs and symptoms of a stroke may include an inability to move or feel on one side of the body, problems understanding or speaking, dizziness, or loss of vision to one side. Signs and symptoms often appear soon after the stroke has occurred (Daniel, 1972). If symptoms last less than one or two hours, the stroke is a transient ischemic attack (TIA), also called a ministroke. A hemorrhagic stroke may also be associated with a severe headache (Guldvog, 1998). The symptoms of a stroke can be permanent. Long-term complications may include pneumonia and loss of bladder control (Srinivasan, 1984).

The main risk factor for stroke is high blood pressure (Calenda, 2016). Other risk factors include obesity, high blood cholesterol, diabetes mellitus, a previous TIA, end-stage kidney disease, and atrial fibrillation (Esenwa, 2016; Arboix, 2015). An ischemic stroke is typically caused by blockage of a blood vessel, though there are also less common causes (Bang, 2015). A hemorrhagic stroke is caused by either bleeding directly into the brain or into the space between the brain's membranes. Bleeding may occur due to a ruptured brain aneurysm (Poungvarin, 1991). Diagnosis is typically based on a physical exam and supported by medical imaging such as a CT scan or MRI scan (Ferro, 1998). A CT scan can rule out bleeding, but may not necessarily rule out ischemia, which early on typically does not show up on a CT scan.

Other tests such as an electrocardiogram (ECG) and blood tests are done to determine risk factors and rule out other possible causes. Low blood sugar may cause similar symptoms ( Bang, 2015).

Prevention includes decreasing risk factors, surgery to open up the arteries to the brain in those with problematic carotid narrowing, and warfarin in people with atrial fibrillation. Aspirin or statins may be recommended by physicians for prevention. A stroke or TIA often requires emergency care. An ischemic stroke, if detected within three to four and half hours, may be treatable with a medication that can break down the clot. Some hemorrhagic strokes benefit from surgery. Treatment to attempt recovery of lost function is called stroke rehabilitation, and ideally takes place in a stroke unit; however, these are not available in much of the world.

In 2013, approximately 6.9 million people had an ischemic stroke and 3.4 million people had a hemorrhagic stroke. In 2015, there were about 42.4 million people who had previously had a stroke and were still alive (Ntaios, 2015). Between 1990 and 2010 the number of strokes which occurred each year decreased by approximately $10 \%$ in the developed world and increased by $10 \%$ in the developing world (Li, 2015). In 2015, stroke was the second most frequent cause of death after coronary artery disease, accounting for 6.3 million deaths (11\% of the total). About 3.0 million deaths resulted from ischemic stroke while 3.3 million deaths resulted from hemorrhagic stroke. About half of people who have had a stroke live less than one year. Overall, two thirds of strokes occurred in those over 65 years old (Ma, 2019).

\section{Patients and Methods}

This study was conducted in Nangarhar University Teaching Hospital, Neurology and Radiology department, Faculty of Medicine, Nangarhar University, Afghanistan. This is the only hospital that has specialized neurology services in eastern of Afghanistan. 401 consecutive patients with acute stroke presenting within 48 hours of onset were included in the study. World Health Organization criteria for the acute stroke was adopted, namely rapid 
onset of clinical signs of focal or global cerebral dysfunction lasting 24 hours or leading to death with no apparent cause other than a vascular lesion. History taking and through neurological and general physical examinations were conducted on each patient. Investigations included blood counts, routine blood chemistry and electrocardiography, Brain $\mathrm{CT}$,other investigation like echocardiography, carotid Doppler ultrasound and angiography were possible to perform when appropriate in a limited number of patients. Brain CT scan was done for all patients. the assessment of stroke type was based on brain CT scan and the clinical variables, including level of consciousness, symptoms of increased intracranial pressure (headache, vomiting), blood pressure, and atheromatous markers (diabetes, angina, claudication).

\section{Results}

401 patients were included in the study. There were 215 (53.6\%) males and 186 (46.4\%) females, with a male-to-female ratio of 1.15:1. Their ages ranged between $20-100$ years, with a peak frequency (33\%) in the age group 61 to 70 years (Table 1 ).

Table 1. Age distribution of patients with acute stroke.

\begin{tabular}{l|l} 
Age $(y r)$ & NO(\%) \\
\hline $20-30$ & 5 \\
$31-40$ & 16 \\
$41-50$ & 45 \\
$51-60$ & 96 \\
$61-70$ & 134 \\
$71-80$ & 83 \\
$81-90$ & 18 \\
$91-100$ & 4 \\
Total & $401(100 \%)$
\end{tabular}

The majority of patients (62\%) were from Nangarhar province. The remaining $38 \%$ were from Laghman,Konar,Noristan, Kabul,Kapisa and Paktia pronvinces .

309 (77.1\%) patients had cerebral infarction and 92 (22.9\%) had intracerebral hemorrhage. There was no incidence of subarachnoid hemorrhage. The frequency of associated risk factors is shown in Table 2

Table 2. Frequency of risk factors in patients with stroke.

\begin{tabular}{l|ll} 
Risk factors & No of patients & percentage \\
\hline hypertention & 159 & 39.6 \\
Heart disease & 63 & 15.7 \\
Diabetes mallitus & 58 & 14.4 \\
Previus TIA & 35 & 8.7 \\
Blood disorder & 16 & 3.9 \\
Obesity & 14 & 3.4 \\
Multiple risk factors & 56 & 13.9
\end{tabular}


Thirty patients 109 (27.1\%) died, 38 had hemorrhagic stroke, and 71 had infarction. Most of the deaths (75\%) occurred within 48 hours of hospital admission. At the time of discharge, $185(46.1 \%)$ of the stroke survivors remained with some significant degree of neurological deficit, while 75 (18.7\%) regained good function.

\section{Discussion}

Hospital-based prospective study, despite its known limitations, continues to be an effective means for finding out disease indices in countries where it is difficult to conduct proper neuroepidemiological studies (Al-Rajeh S, 1998). In our experience, the diagnosis of stroke type by clinical criteria was nearly same to Brain CT examination was. It is known that bedside diagnosis of stroke can be reached by meticulous clinical methods in $85 \%$ to $90 \%$ of cases, even by the non neurologist. it is possible to distinguish hemorrhagic from ischemic strokes with over $90 \%$ accuracy. Hemorrhagic stroke was more common in our patients $(22.9 \%)$ than that reported in western populations (Synhaeve, 2014).

It is more likely that a great proportion of patients with hemorrhagic rather than ischemic stroke came and were admitted to the hospital because of their more dramatic and critical clinical presentation. The peak age group, 61 to 70 years, is 2 decades earlier than in developed countries. Similar distribution was seen in studies from India, Nigeria, and Saudi Arabia. These observations were explained by reduced life span and a smaller proportion of elderly population in tropical countries. The global tendency of male preponderance was also observed in our series, where men constituted nearly two thirds of the patients. The common risk factors observed in our patients were the same as those seen worldwide. Similarly, as well, hypertension continued to be the major risk factor (Towfighi 2012). The role of hypertension was probably made more important by the inadequate blood pressure control observed in a large number of our patients. The main reason for that was failure of treatment compliance because of drug costs and availability problems. Obesity and diabetes mellitus are important risk factors in developing countries, particularly in the younger age groups. Limited use of anticoagulant therapy because of monitoring difficulties has obviously added to the stroke risk in heart disease. Most of the mortality in our patients occurred in the hemorrhagic stroke group in the first few days of admission (Kurth, 2006). The overall mortality was higher than in western and more prosperous developing countries. That outcome was attributed to the higher proportion of hemorrhagic strokes, and their management in general medical wards lacking facilities of intensive care and expertise of an acute stroke unit (Park, 2011) .

\section{Conclusion}

Stroke in eastern region of Afghanistan has similar risk factors as elsewhere, and its mortality is higher than in western and wealthier developed countries. Encouraging health authorities to improve quality of hypertension control and to develop special hospital care for acute stroke patients is needed to reduce morbidity and mortality of the disease in eastern region of Afghanistan and similar developing countries.

\section{Stroke Prevention}

The aim of stroke prevention is to decrease stroke incidence through targeted modification of a single risk factor, or a cluster of multiple risk factors, employed on a population, community, or individual level. In some cases, however, as with the use of anti-platelets, the goal may be to use an intervention that is known to reduce ischemic stroke risk among those who are deemed to be at elevated risk, rather than as a treatment for a specific risk factor. 
There are three broad levels of stroke prevention: 1) primordial prevention is the most generalizable, and broadly deals with healthy living measures that, when applied on a group level, aim to decrease the population incidence of physiologic stroke risk factors; 2) primary prevention, which aims to improve the risk factor profile of individuals who do not have a history of stroke or TIA with the goal of preventing a first cerebrovascular event; and 3) secondary prevention, which is the most targeted and is only employed after an individual has suffered a stroke or TIA, with the goal of preventing stroke recurrence. Examples of primordial stroke prevention include efforts to encourage smoking cessation, a healthy diet, increased physical activity, and weight control. Primary and secondary stroke prevention target a person's specific lifestyle-related and medical stroke risk factors, like hypertension and diabetes. We will focus this discussion on primordial and primary prevention of ischemic stroke.

\section{References}

Towfighi, A. D. M. (2012). Impact of a healthy lifestyle on all-cause and cardiovascular mortality after stroke in the USA,. J. Neurol. Neurosurg(83 ), 146-151.

Al-Rajeh, S. L. E. (1998). Stroke register: Experience from the Eastern Province of Saudi Arabia. Cerebrovasc Dis, 86-89.

Arboix, A. (2015). Cardiovascular risk factors for acute stroke: risk profiles in the different subtypes of ischemic stroke. World J. Clin, 3, 418-429.

Calenda, B. W. V. F. (2016)). Stroke risk assessment in atrial fibrillation: risk factors and markers of atrial myopathy. Nat. Rev. Cardiol, 13, 549-559.

Bogousslavsky, J. C. (1997). Early classification of stroke. Cerebrovasc Dis, 5, 7.

Esenwa, C. C. A. M. (2016). nflammatory risk factors, biomarkers and associated therapy in ischaemic stroke. Nat. Rev. Neurol, 12, 594-604.

Daniel, M. A. (1972). General characteristics of the stroke population: spects of cerebrovascular disease in India.,. Medras, India: Medras Dioceson Press, 4-10.

Ferro, J. M. P. A. (1998). Diagnosis of stroke by the nonneurologist. A validation study. Stroke, 1106-1109.

Ntaios, G. V. P. (2015). Embolic strokes of undetermined source in the Athens stroke registry: a descriptive analysis. Stroke, 46 .

Guldvog, B. R. (1998). Stroke unit versus general medical ward II. Neurological deficits and activities of daily living Stroke, 29, 586-590.

Management. (1998). Asian Pacific Concensus Form on stroke. 29, 1730-1736.

Synhaeve, N. E. R. A. (2014). Poor long-term functional outcome after stroke among adults aged 18 to 50 years: Follow-Up of Transient Ischemic Attack and Stroke Patients and Unelucidated Risk Factor Evaluation (FUTURE) study, 45. Stroke(45), 1157-1160.

Bang, J. K. (2015). Association of the metabolic syndrome with intracranial atherosclerotic stroke. Neurology, 65, 296-298.

Bang, J. K. (2015). Association of the metabolic syndrome with intracranial atherosclerotic stroke. Neurology, 65 , 296-298.

Osuntoua, B. O. (1979). Incidence of stroke registry at Ibadan, Nigeria-75. Stroke. 10, 197375.

Poungvarin, N. V. A. (1991). stroke score and validation study to distinguish supratentorial intracerebral hemorrhage from infarction. BMJ, 302, 15651567.

Srinivasan, K. (1984). Ischemic cerebrovascular disease in the young. Two common causes in India. 12, 460- 466. 
INTERNATIONAL JOURNAL OF ACADEMIC RESEARCH IN PROGRESSIVE EDUCATION AND

DEVELOPMENT

Vol. 11, No. 1, 2022, E-ISSN: 2226-6348 @ 2022 HRMARS

Kurth, T. S. M. (2006). Healthy lifestyle and the risk of stroke in women. Arc Intern. Med, 166 , 1403-1409.

Wolf, P. A. K. W. (1998). Epidemiology of stroke. In: Cerebrovascular disease. Blackwell Science, 2, 834- 849 . 